\title{
Photoinduced Thermal Copper Reduction onto Gold Nanocrystals under Potentiostatic Control $^{\dagger}$
}

\author{
Peter L. Redmond,* Erich C. Walter, and Louis E. Brus \\ Chemistry Department, Columbia University, New York, New York 10027
}

Received: June 8, 2006; In Final Form: July 17, 2006

\begin{abstract}
We study the photoreduction of adsorbed copper ions onto Au nanoparticles, on an indium tin oxide (ITO) electrode in an aqueous electrochemical cell, as a function of applied voltage and laser intensity. The photocurrent is a nonlinear function of laser intensity and increases sharply with cathodic voltage in the underpotential deposition region. The photoreduction is attributed to laser heating of the Au nanoparticles rather than "hot electron" processes. Numerical simulation of the Butler-Volmer kinetic equation using experimental parameters predicts a several orders of magnitude increase in current for a temperature rise of a few Kelvin.
\end{abstract}

\section{Introduction}

In 2003, we reported that low-intensity optical plasmon irradiation, in aqueous $\mathrm{Ag}$ colloids, photocatalyzes adsorbed $\mathrm{Ag}^{+}$ reduction, leading to particle growth. ${ }^{1}$ The irradiation wavelength controls the particle shape. Plasmon excitation can also photocatalyze small Ag colloid reformulation into large truncated prisms, and even fusion of such prisms into yet larger prisms. ${ }^{2,3}$ The mechanisms of these processes are not well understood. The Ag electrochemical potential, unknown in these colloidal experiments, should be a critical parameter. We now describe optically induced $\mathrm{Cu}^{2+}$ reduction onto gold nanoparticles under electrochemical potential control on a transparent indium tin oxide (ITO) electrode. We explore both singleelectron excitation and thermal heating mechanisms. Our present data are best understood as laser heating, causing a temperature rise of just a few Kelvin. Simulations of the Butler-Volmer equation within our underpotential deposition conditions show that such a modest temperature rise can increase the reduction current by 1 or 2 orders of magnitude.

Von Gutfeld et al. first reported laser-induced thermal electroplating in $1979 .{ }^{4}$ Electrode laser heating processes have been systematically explored by these workers and others subsequently..$^{5-10}$ Recently, Lowe et al. studied the photocurrent response of $10 \mathrm{~nm}$ gold nanoparticles attached to ITO by organic molecule linkers. ${ }^{11}$ They found that laser irradiation of the nanoparticle-coated slides caused temperature jumps of 2.5$40{ }^{\circ} \mathrm{C}$, depending on the nanoparticle surface density on the slide. This was correlated with a $9 \mathrm{mV}$ open circuit potential change of the ferrocene/ferrocinium redox couple. At much higher optical intensities, pulsed lasers transiently excite metal nanoparticles to extremely high electron temperatures and can not only induce fragmentation ${ }^{12-17}$ but also fusion. ${ }^{18,19}$

Silver particles on conductive substrates, such as ITO, undergo an electrochemical Oswalt ripening process ${ }^{20,21}$ in which larger particles grow at the expense of smaller ones in aqueous solution. To eliminate this complication, in this study, we use $\mathrm{Au}$ rather than $\mathrm{Ag}$. We do not observe ripening of $\mathrm{Au}$ particles lithographically patterned on ITO over periods of

\footnotetext{
† Part of the special issue "Arthur J. Nozik Festschrift".

* Corresponding author. E-mail: plr2001@columbia.edu.
}

several hours. This may be due to the low equilibrium exchange current density of gold $\left(\mathrm{Au} \mid \mathrm{Au}^{+} \approx 0.3 \mathrm{~mA} / \mathrm{cm}^{2}\right)$ as compared with silver $\left(\mathrm{Ag} \mid \mathrm{Ag}^{+}=26 \mathrm{~mA} / \mathrm{cm}^{2}\right) \cdot{ }^{22,23}$ Furthermore, gold is only soluble in solutions containing cyanide or halogens. ${ }^{24}$ Metal ion solubility is necessary for electrochemical Oswald ripening.

\section{Experimental Methods}

Square arrays of gold nanoparticles (typical radius $=37.5$ $\mathrm{nm}$ ) were prepared using standard electron beam lithography on indium tin oxide (ITO) coated glass working electrodes (thickness $=140 \pm 10 \mathrm{~nm}$, resistivity $=20 \pm 5 \Omega / \mathrm{sq}$, Thin Film Devices). Array sizes were typically $50 \mu \mathrm{m} \times 50 \mu \mathrm{m}$ and contained about 40000 particles, with nearest neighbor spacings of about $250 \mathrm{~nm}$. After resist developing, $5 \mathrm{~nm}$ of chromium and $35 \mathrm{~nm}$ of gold were evaporated onto the pattern at a deposition rate of $0.1 \mathrm{~nm} / \mathrm{s}$ and under a vacuum of $10^{-6}$ Torr. After resist liftoff, these evaporated $\mathrm{Au}$ particles were annealed in a nitrogen atmosphere at $600{ }^{\circ} \mathrm{C}$ for $1 \mathrm{~h}$ in order to improve crystalline quality and shape. The working area of the ITO electrode was subsequently reduced to a $500 \mu \mathrm{m} \times 500 \mu \mathrm{m}$ window centered on the array in a second lithographic process with poly(methyl methacrylate). Scanning electron micrographs (SEM) of the sample were taken using a Hitachi 4700 scanning electron microscope.

The Au array-ITO working electrode was used as a bottom window in a photoelectrochemical cell containing $200 \mathrm{mM}$ aqueous $\mathrm{CuSO}_{4}$. A gold wire served as the pseudoreference electrode. The counter electrode was a platinum foil. Nitrogen was bubbled through the solution for at least $15 \mathrm{~min}$ before experimental runs. A Coherent Innova 300 argon-ion laser (514.5 nm line) was chopped at $1 \mathrm{~Hz}$ and focused to a $50 \mu \mathrm{m}$ diameter spot illuminating the Au array. Current was measured using a Princeton Applied Instruments 2263 potentiostat. Photocurrent is defined as the difference between the current with the laser on and the laser off.

\section{Results}

We use a copper sulfate concentration of $200 \mathrm{mM}$ to ensure adsorbed $\mathrm{Cu}^{2+}$ on the $\mathrm{Au}$ particles. At this high concentration, copper sulfate acts as its own supporting electrolyte and 
A.

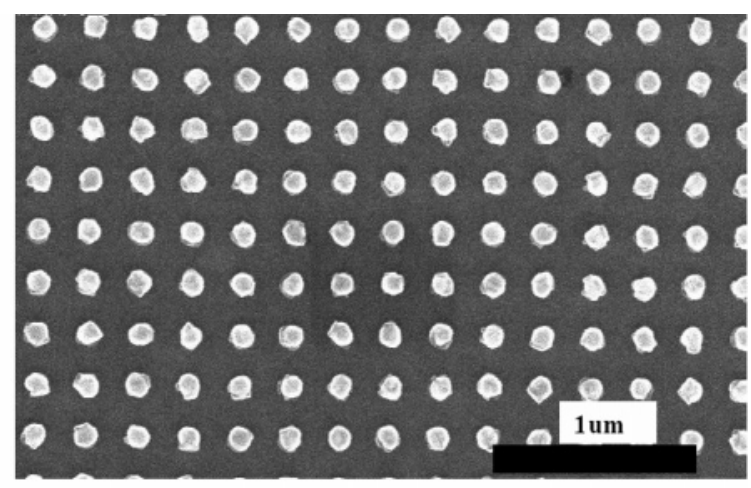

B.

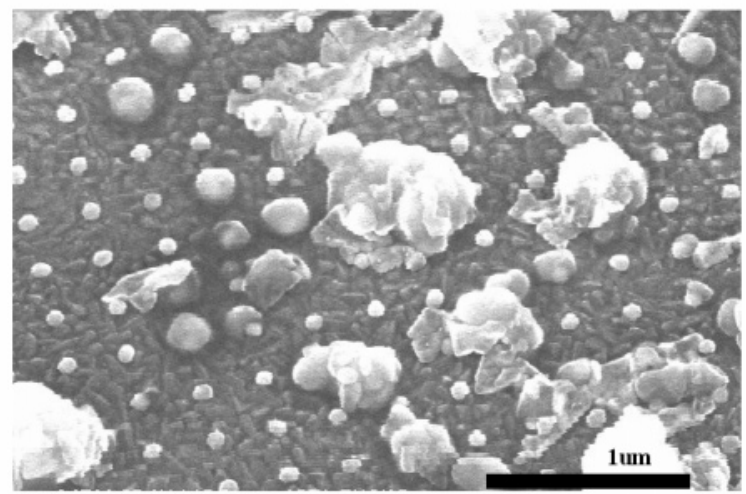

Figure 1. SEM images of gold nanoparticle arrays before (A) and after (B) irradiation under potentiostatic control, as described in the text.

eliminates mass-transfer effects in the cell current. Figure S1 (Supporting Information) shows a cyclic voltamogram (0 to $-0.6 \mathrm{~V}$ ) of a gold-particle-coated ITO cathode. Underpotential deposition of copper on gold is known to occur at potentials shifted $100-200 \mathrm{mV}$ from the cathodic peak potential. ${ }^{25,26} \mathrm{We}$ observe an underpotential deposition peak at about $-0.254 \mathrm{~V}$ and an increasing reduction wave at $-0.400 \mathrm{~V}$ and below. This is consistent with the calculated $\mathrm{Cu}^{2+}$ on $\mathrm{Cu}$ formal redox potential of $-0.446 \mathrm{~V}$ vs $\mathrm{Au}$ wire (see Supporting Information). ${ }^{27}$ At our high $\mathrm{Cu}^{2+}$ concentration in the underpotential -0.1 to $-0.3 \mathrm{~V}$ range, the resistance of the electrochemical cell should be dominated by electron-transfer resistance at the cathode. In agreement with this, we observe a linear Tafel plot in Figure S3 (Supporting Information). We analyze this plot for kinetic parameters in the Discussion Section

We observe $\mathrm{Cu}$ photodeposition in the underpotential deposition range. Figure $1 \mathrm{~B}$ shows a nanoparticle array held at a potential of $-250 \mathrm{mV}$ and excited at $\sim 4 \times 10^{4} \mathrm{~W} / \mathrm{cm}^{2}$ for $5 \mathrm{~s}$. Under laser exposure, a cathodic photocurrent on the order of microamps flowed in the cell. This is in contrast with typical dc dark currents of $20 \mathrm{nA}$ at such potentials. No boiling was observed, apparently because water effectively removes laser irradiation heat. Reduced $\mathrm{Cu}$ is observed on the array after illumination. $\mathrm{Cu}$ deposits in a core/shell fashion on some (but not all) illuminated $\mathrm{Au}$ particles. There were also irregular $\mathrm{Cu}$ deposits spanning several Au particles.

In separate experiments on other arrays, no photocurrent, or detectable $\mathrm{Cu}$ in the SEM image, was observed at potentials more positive than $-100 \mathrm{mV}$. Irradiation of an ITO electrode without $\mathrm{Au}$ particles at $-250 \mathrm{mV}$ did not yield photocurrent or observable copper deposition. In addition, holding the gold particles at a potential of $-250 \mathrm{mV}$ in the copper solution for a time of $60 \mathrm{~min}$ in the absence of laser light yielded no detectable deposition. From this, we conclude that the irradiation of Au particles (and not ITO) held at such negative potentials
A.

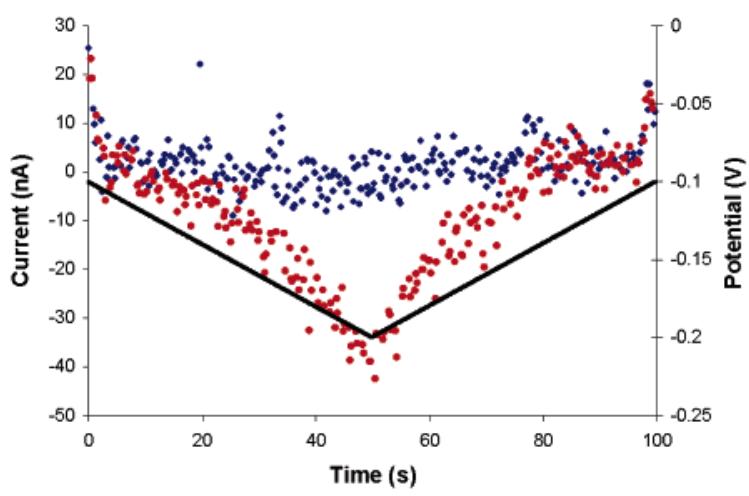

B.

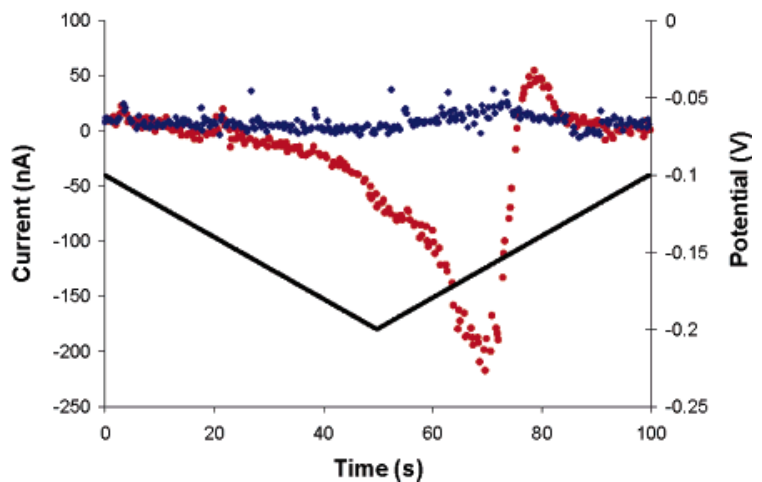

Figure 2. (A, B) Plots of the time vs current and potential of the particles: the blue dots are the dark current and the red dots are the illuminated current (left axis). The black lines are the potential of the particles vs a gold wire (right axis). Scan rate: $2 \mathrm{mV} / \mathrm{s}$.

causes initial deposition of $\mathrm{Cu}$. However, $\mathrm{Cu}$ nucleation and growth are not uniform. The actual voltage on each Au particle may vary due to contact-resistance differences with the ITO.

With continued irradiation and, hence, deposition, the total photoactive area of $\mathrm{Au}$ and $\mathrm{Cu}$ electrode surface increases, thus complicating interpretation. Experiments were performed to determine conditions under which the cumulative copper deposition did not significantly affect the photocurrent at a fixed potential. In Figure 2, the potential was swept negative and then positive over the range of -0.100 to -0.200 V. In Figure 2A, the photocurrent followed the potential symmetrically, thus copper deposited during the negative sweep did not affect the photocurrent at the same voltages in the positive sweep. The total integrated charge passed during irradiation was $\sim 65 \mathrm{nC}$ (tens of nanoamps over a time of roughly a minute). This corresponds to a hypothetical coverage of $1.5 \mathrm{~nm}$ of copper added radially to each $\mathrm{Au}$ nanoparticle in the laser spot. In this case, the photodeposited $\mathrm{Cu}$ is about $10 \%$ of the initial Au mass. In Figure 2B, at higher laser power and at hundreds of nanoamps current, the photocurrent did not follow the potential symmetrically. Significant photodeposited $\mathrm{Cu}$ formed on the $\mathrm{Au}$ particles and contributed to the absorption of light, and in the return voltage sweep, this $\mathrm{Cu}$ was oxidized. This is seen as positive current around $80 \mathrm{~s}$. The integrated charge was $\sim 260$ $\mathrm{nC}$.

As shown above, the deposition of copper limits our photocurrent dynamic range. We cannot work with a photocurrent above a few tens of nanoamps for more than a minute before $\mathrm{Cu}$ deposition changes the electrode. Within this limitation, we measured the photocurrent laser intensity dependence at a fixed potential of $-200 \mathrm{mV}$ (see Figure 3). All of the data plotted in Figure 3 were tested for reversibility as described above. The red data points were taken for a laser spot size of $75 \mu \mathrm{m}$, the blue points for a spot size of $100 \mu \mathrm{m}$. Figure 3 shows the 


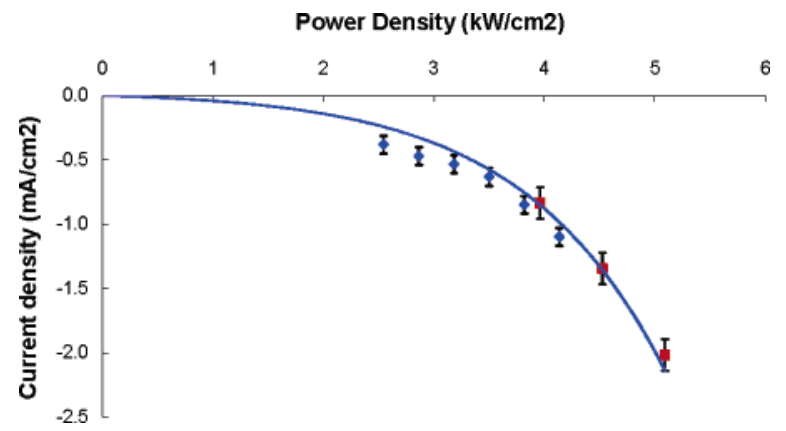

Figure 3. Plot of the photocurrent (i.e., dark current subtracted) density at $-200 \mathrm{mV}$ vs laser intensity.

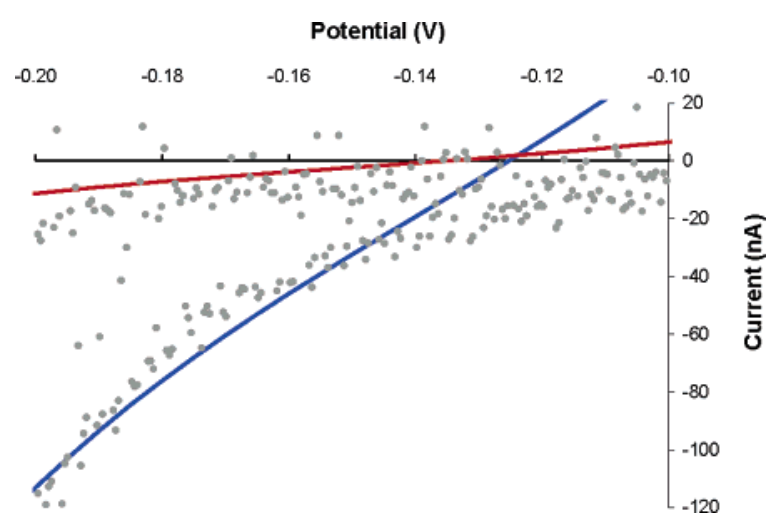

Figure 4. Plot of potential vs current: the gray dots are raw experimental data, the blue line is the calculated Butler-Volmer current (eq 1) with an assumed temperature increase of $22 \mathrm{~K}$, the red line is the calculated Butler-Volmer current at room temperature $(298 \mathrm{~K})$. The laser power density was $5.1 \mathrm{~kW} / \mathrm{cm}^{2}$.

photocurrent density is strongly nonlinear as a function of laser intensity. Figure 4 shows the photocurrent as a function of voltage for fixed laser intensity.

\section{Discussion}

The laser heats the $\mathrm{Au}$ particles; thus we now consider possible increased $\mathrm{Cu}^{2+}$ reduction due to temperature rise of the $\mathrm{Au}$ particles. In the following calculation, we find a strong temperature dependence in our underpotential deposition regime. The Butler-Volmer kinetic equation for electrochemical current is $28-32$

$$
\begin{gathered}
i=i_{\mathrm{o}}[\exp (-\alpha f \eta)-\exp ((1-\alpha) f \eta)] \\
J_{\mathrm{o}}=\frac{i_{\mathrm{o}}}{A}=n F\left(\frac{k T}{h}\right) a_{\mathrm{o}} \exp \left[\left(-\Delta G^{\mathrm{act}}+\alpha F E_{\mathrm{eq}}\right) / R T\right]
\end{gathered}
$$

Here, $i$ is the current in amps, $i_{\mathrm{o}}$ is the exchange current, $\alpha$ is the transfer coefficient, $f=F / R T, F$ is Faraday's constant $\left(9.65 \times 10^{4} \mathrm{C}\right), R$ is the molar gas constant $(8.31 \mathrm{~J} / \mathrm{mol} \cdot \mathrm{K}), T$ is temperature in Kelvin, $\eta=E-E_{\mathrm{eq}}, E$ is the potential in volts, $E_{\text {eq }}$ is the equilibrium potential for copper reduction in volts, $J_{\mathrm{o}}$ is the exchange current density in $\mathrm{A} / \mathrm{cm}^{2}, A$ is the area of the electrode in $\mathrm{cm}^{2}, n$ is the number of electrons transferred in the reduction, $k$ is Boltzman's constant $\left(1.38 \times 10^{-23} \mathrm{~J} / \mathrm{K}\right)$, $h$ is Plank's constant $\left(6.626 \times 10^{-34} \mathrm{~J} / \mathrm{s}\right), \Delta G^{\text {act }}$ is the standard Gibbs free energy of activation in $\mathrm{J} / \mathrm{mol}$, and $a_{\mathrm{o}}$ is the activity of the oxidized species (in our case: $\mathrm{Cu}^{2+}$ ) in molarity $/ \mathrm{cm}^{2}$ but is inserted in the equation as $1 / \mathrm{cm}^{2}$.

The transfer coefficient $\alpha$ and exchange current $i_{0}$ were obtained from the slope $[=(1-\alpha) F /(2.3 R T)]$ and the $y$-axis intercept $\left[=\log \left(i_{\mathrm{o}}\right)\right]$ of the Tafel plot shown in Figure S3

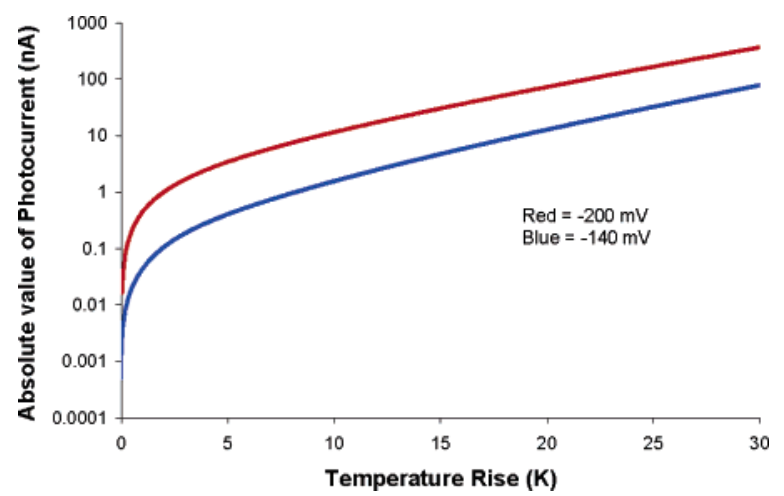

Figure 5. Plot of the calculated photocurrent, above the roomtemperature current, on log scale vs temperature rise: The blue curve is for $E=-140 \mathrm{mV}$ and the red curve is for $-200 \mathrm{mV}$. We assume a laser spot size radius of $100 \mu \mathrm{m}$ on a square array of $r=37.5 \mathrm{~nm}$ gold nanoparicles with a center-to-center distance of $250 \mathrm{~nm}$. The calculated net total $298 \mathrm{~K}$ current (not shown) is $1.52 \times 10^{-10} \mathrm{~A}$ for $-140 \mathrm{mV}$ and $2.26 \times 10^{-8} \mathrm{~A}$ for $-200 \mathrm{mV}$.

(Supporting Information). The room-temperature fit of the exchange current was used to set the $\Delta \mathrm{G}^{\text {act }}$ using eq 2 . We found an $\alpha$ of 0.437 , an $i_{\mathrm{o}}$ of $4.1 \times 10^{-9} \mathrm{~A}$, and a $\Delta G^{\text {act }}$ of $1.19 \times$ $10^{5} \mathrm{~J} / \mathrm{mol}$ at room temperature. For comparison, Varvara et al. obtained an $\alpha$ of 0.500 and an exchange current density of 8.90 $\times 10^{-3} \mathrm{~A} / \mathrm{cm}^{2}$ for the reduction of copper on copper. ${ }^{33}$ Dividing the exchange current from the Tafel plot by the area of the gold nanoparticles gives a current density of $2.9 \times 10^{-5} \mathrm{~A} / \mathrm{cm}^{2}$. The low measured current density may be due to the inactivity of some of the nanoparticles and from the fact that we are depositing $\mathrm{Cu}$ on $\mathrm{Au}$. The thermodynamic $E_{\mathrm{eq}}$ was measured to be $-135 \mathrm{mV}$ vs Au wire at room temperature and $200 \mathrm{mM}$ $\mathrm{Cu}^{2+}$ concentration. We assumed that this value shifts with temperature at a rate of $0.5 \mathrm{mV} / \mathrm{K}$, as was measured for the $\mathrm{Cu}_{(\mathrm{s})} \mid \mathrm{Cu}^{2+}{ }_{(\mathrm{aq})}$ redox couple by Lewanowski et al. ${ }^{34}$

With all the parameters in the Butler-Volmer equation now determined, we plot in Figure 5 the calculated photocurrent vs temperature rise. A temperature rise of just several degrees increases the reduction current by tens of nanoamps. The curve shows two characteristic regions. The very rapid rise below 4 degrees is an increasing difference between large, and nearly equal, reduction and oxidation counter-currents. At $298 \mathrm{~K}$ for $-140 \mathrm{mV}$, the calculated reduction contribution to the net current is $8.84 \times 10^{-10} \mathrm{~A}$ and the oxidation contribution to the net current is $7.32 \times 10^{-10} \mathrm{~A}$. As temperature rises, the reduction current increases and the oxidation current decreases. The second region above 4 degrees corresponds to thermal activation of reduction current, with the oxidation current no longer comparable in magnitude.

In the Supporting Information, we estimate the laser-induced temperature rise using the known optical absorption and thermal transport properties of $\mathrm{Au}$ particles in water. ${ }^{35}$ Our intensities of $10^{3}-10^{4} \mathrm{~W} / \mathrm{cm}^{2}$ are far below the values necessary for melting or reformulation of colloidal $\mathrm{Au}$ particles. ${ }^{36-38} \mathrm{We}$ calculate that the electron temperature should be very close to the Au lattice temperature. We assume a spherical Au particle in an infinite aqueous medium. For a gold particle of radius $37.5 \mathrm{~nm}$ in water, the Mie absorption cross section is $1.4 \times$ $10^{-14} \mathrm{~m}^{2}$ and the Mie scattering cross section is $4.9 \times 10^{-15}$ $\mathrm{m}^{2}$. Figure S5 (Supporting Information) shows that the particle and nearby solution (within a few $\mathrm{nm}$ ) will have the same temperature increase. At our high copper concentrations, and with a relatively small temperature rise, we do not expect the temperature gradient to have a significant effect on the electrode kinetics. At lower concentrations, where mass-transfer effects 
become important, the temperature gradient may cause microstirring of the solution and significantly affect the electrode kinetics. At the highest power density used in Figure 3, $5.1 \mathrm{~kW} /$ $\mathrm{cm}^{2}$, the calculated temperature increase is only about 2.5 degrees. In the particle arrays, the nanoparticles would also "feel" the heat of its neighboring particles. Thus the actual temperature increase would be larger. This order of magnitude calculation is consistent with our photocurrent data.

Figure 4 shows a plot of current vs potential of an experimental run plotted with predicted Butler-Volmer current. The experimental data in Figure 4 were obtained using a gold nanoparticle pattern with $r=37.5 \mathrm{~nm}$, a center-to-center distance of $250 \mathrm{~nm}$, a laser spot diameter of $100 \mu \mathrm{m}$, and a laser power density of $5.1 \times 10^{3} \mathrm{~W} / \mathrm{cm}^{2}$. The laser was chopped so that the top dots correspond to zero laser intensity and the bottom dots correspond to full laser intensity. The ButlerVolmer current traces presented in Figure 4 were calculated using eq 1 and used the experimentally determined $\alpha, E_{\mathrm{eq}}$, and $\Delta G^{\text {act }}$ listed above. The red current trace has $T=298 \mathrm{~K}$. The blue current trace fits the data well for $T=320 \mathrm{~K}$; this is the only adjustable parameter. The Butler-Volmer current traces predict positive current below the equilibrium potential through the oxidation of bulk copper. The experimental data did not show positive current below the equilibrium potential because there was no bulk copper to oxidize.

For small increases, the particle temperature rise should be linear with laser intensity. Therefore, the Butler-Volmer current calculation in Figure 5 predicts a nonlinear dependence of photocurrent with laser intensity at fixed voltage, as experimentally observed in Figure 3. The Butler-Volmer model fit is the solid blue line with an assumed temperature of $323 \mathrm{~K}$ for $5.1 \times 10^{3} \mathrm{~W} / \mathrm{cm}^{2}$. We see that the Butler-Volmer equation reasonably describes the photocurrent response in both Figures 3 and 4.

The expected temperature rise of a few degrees can semiquantitatively explain our measured photocurrent. The temperature-related photocurrent is large because we are in the underpotential deposition regime where reduction is activated and because the self-exchange currents are relatively large. There is also a relatively minor thermodynamic contribution due to the shift in the rest potential with temperature.

Are there nonthermal "hot electron" processes operating as well? Laser-initiated transient electron transfer to adsorbed molecules is thought to occur in the "chemical" aspect of SERS. ${ }^{39,40}$ Laser irradiation can also cause nonthermal photochemistry on metal surfaces. ${ }^{41}$ Fishelson et al. studied the photoelectrochemical response of gold-dithiol particle films. ${ }^{42}$ They reported the photoemission threshold of creating solvated electrons as a function of potential in an electrochemical cell and found the photoemission threshold of gold-dithiol nanoparticle films to be $\sim 3.5 \mathrm{eV}$ at a potential of $-200 \mathrm{mV}$. We excited our particles at $514.5 \mathrm{~nm}(2.41 \mathrm{eV})$, which is well below the photoemission threshold at our potentials. This suggests that we are not ejecting electrons into solution in the form of solvated electrons.

We now consider the potential role of ITO in our photocurrent experiments. The ITO, as well as the gold nanoparticles, is photoexcited by the laser. ITO has $90 \%$ transmittance at 514.5 nm. As a control experiment, ITO was photoexcited in the absence of gold nanoparticles and no photocurrent or photodeposition was detected. From this we conclude that electronic excitation of the ITO does not significantly contribute to the photocurrent. Groups have studied the photocurrent generated by exciting plasmons of nanoparticles deposited on titanium

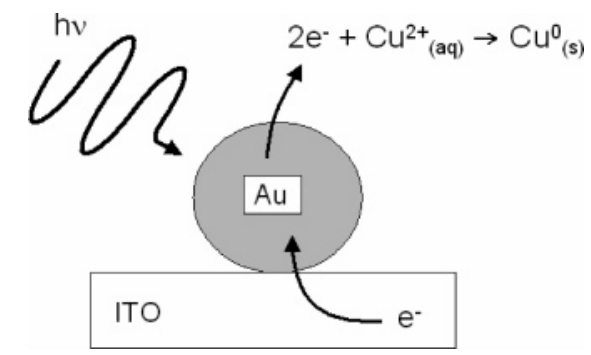

Figure 6. Proposed mechanism for the photoelectrochemistry: light induces heating of the nanoparticles which causes a rest potential shift and increase in the charge-transfer rate in the reduction of adsorbed copper ions. The ITO electrode replaces lost gold electrons to maintain the potential set by the potentiostat.

dioxide. ${ }^{43-45}$ Here, charge separation occurs when photoexcited electrons from the gold nanoparticles transfer into the conduction band of the titanium dioxide and the hole is transferred from the gold nanoparticles to a redox carrier in solution. We do not have a redox carrier to carry photogenerated holes from the gold nanoparticles. Gold nanoparticle arrays where photoexcited in a solution of potassium sulfate (i.e., in the absence of copper sulfate). No photocurrent was detected. We conclude that the photocurrent comes from the charge transfer of electrons from the gold nanoparticles into adsorbed copper ions (causing a reduction) and compensative electrons are transferred from the ITO electrode into the gold, as can be seen in Figure 6.

Single-electron excitations might tunnel into adsorbed copper states that are lower in energy than the solvated electron state. ${ }^{46,47} \mathrm{We}$ do not have one photon excited tunneling, as the photocurrent is strongly nonlinear. However, Figure S6 (Supporting Information) shows that the data approximately fit twophoton (intensity squared) excited tunneling, although the intercept is somewhat above the origin. This experiment does not have the dynamic range in either voltage or laser intensity to carefully separate laser heating and a two photon processes. We have shown laser heating must be present. A thermal effect in the Butler-Volmer equation is consistent with the interpretation of early laser-induced copper deposition studies by von Gutfeld and colleagues. ${ }^{4-7}$ Our study shows how significant the heating photocurrent can be for small temperature rises in underpotential deposition. It is possible there is some additional two-photon tunneling photocurrent.

Several studies have considered noble metal nanoparticles in photovoltaic devices. ${ }^{43-45}$ Our work shows that plasmonic heating of nanoparticles will affect the charge-transfer rate of such photochemical experiments and therefore must be taken into account. Groups have noted morphology changes in noble metal particles when laser heated to temperatures below their melting point in aqueous solutions. ${ }^{48,49}$ It has also been shown that nanoparticle morphology can depend on the potential of the particle on surfaces. ${ }^{18,19}$ At elevated temperatures in aqueous solutions, shifts in electrochemical properties of the nanoparticles could have an impact on their morphology. We observed no morphology changes in the gold nanoparticles as monitored by SEM.

Bjerneld et al. studied the laser-induced growth of silver nanoparticles from aqueous solutions. ${ }^{50}$ They irradiated glass surfaces in contact with solutions of silver nitrate and sodium citrate. Solutions of silver nitrate and sodium citrate are stable at room temperature, but when heated to boiling, the silver is reduced by the citrate. The reduction of silver by citrate is kinetically limited. In their experiments, Bjerneld et al. found that irradiating glass slides with $170-1.7 \times 10^{4} \mathrm{~W} / \mathrm{cm}^{2}$ in solutions of silver nitrate and sodium citrate induces silver 
crystallites to grow on the slide. At such laser power densities, it is possible that a shift in the electrochemical properties due to laser heating of the nanoparticles accelerates the growth of the silver nanoparticles once they have nucleated.

Finally, we return to the wavelength controlled, low light intensity, near-field plasmon photochemical Ag particle growth experiments mentioned in the Introduction. In our present work, we have found a different (thermal) photochemical growth process operating at higher light fluxes. The mechanism of these prior experiments remains to be explored.

\section{Conclusion}

We conclude that lattice heating (through thermalization of single-electron excitations and relaxation of plasmon excitations) gives rise to a shift in the reduction potential of the particles and an increase in the charge-transfer rate, which causes copper to deposit on the nanoparticles. This is both a thermodynamic (shift in rest potential) and kinetic (charge-transfer rate change) change in the properties of the nanoparticles due to laser light irradiation. According to the temperature-modified ButlerVolmer fit and the calculation of temperature rise of the particles, a relatively modest temperature change of about 15 $\mathrm{K}$ is enough to cause measurable difference in the surface properties of gold nanoparticles and facilitate the deposition of copper.

Acknowledgment. This work has been supported by the DOE Basic Energy Sciences FG02-98ER14861, by the Air Force MURI program, by the Columbia NSF Nanocenter CHE010110655, and by the New York Office of Science, Technology, and Academic Research NYSTAR. We have used characterization facilities supported by the Columbia NSF MRSEC Materials Center DMR 0213574.

Supporting Information Available: Cyclic votammograms of gold nanoparticle films, Tafel plot, a plot of the reduction current as the potential was swept negative, a calculation of the electronic and lattice temperature rise of the nanoparticles under irradiation, a plot of the calculated nanoparticle and solution temperature under irradiation, a plot of the photocurrent response vs the square of the laser power density. This material is available free of charge via the Internet at http://pubs.acs.org.

\section{References and Notes}

(1) Maillard, M.; Huang, P.; Brus, L. Nano Lett. 2003, 3, 1611.

(2) Jin, R.; Cao, Y.; Mirkin, C. A.; Kelly, K. L.; Schatz, G. C.; Zheng, J. G. Science 2001, 294, 1901.

(3) Jin R.; Cao, Y. C.; Hao, E.; Metrauz, G. S.; Schatz, G. C.; Mirkin, C. A. Nature 2003, $425,487$.

(4) Gutfeld, R. J.; Tynan, R. L.; Melcher, R. L.; Blum, S. E. Appl. Phys. Lett. 1979, 35, 651.

(5) Puippe, J. Cl.; Acosta, R. E.; von Gutfeld, R. J. J. Electrochem. Soc. 1981, 128, 2539.

(6) von Gutfeld, R. J.; Acosta, R. E.; Romankiw, L. T. IBM J. Res. Dev. 1982, 26, 138.

(7) Smalley, J. F.; Krishnan, C. V.; Goldman, M.; Feldberg, S. W. J. J. Electroanal. Chem. 1988, 248, 255.

(8) Smalley, J. F.; Geng, L.; Feldberg, S. W. J. Electroanal. Chem. 1993, 356, 181

(9) Smalley, J. F.; Chalfant, K.; Feldberg, S. W.; Nahir, T. M.; Bowden, E. F. J. Phys. Chem. B 1999, 103, 1676.

(10) Smalley, J. F.; Geng, L.; Chen, A.; Feldberg, S. W.; Lewis, N. S.; Cali, G. J. Electroanal. Chem. 2003, 549, 13.
(11) Lowe, L. B.; Brewer, S. H.; Kramer, S.; Fuierer, R. R.; Qian, G.; Agbasi-Porter, C. O.; Moses, S.; Franzen, S.; Feldheim, D. L. J. Am. Chem Soc. 2003, 125, 14258.

(12) Logunov, S. L.; Ahmandi, T. S.; El-Sayed, M. A.; Khoury, J. T.; Whetten, R. L. J. Phys. Chem. B 1997, 101, 3713

(13) Mohamed, M. B.; Ahmadi, T. S.; Link, S.; Braun, M.; El-Sayed, M. A. Chem. Phys. Lett. 2001, 343, 55.

(14) Link, S.; El-Sayed, M. A. J. Phys. Chem. B 1999, 103, 8410.

(15) Hodak, J. K.; Martini, I.; Hartland, G. V. Chem. Phys. Lett. 1998 $284,135$.

(16) Hodak, J. K.; Martini, I.; Hartland, G. V. J. Chem. Phys. 2000, 112,5942 .

(17) Shahbazyan, T. V.; Perakis, I. E.; Bigot, J. Y. Phys. Rev. Lett. 1998, 81,3120 .

(18) Fujiwara, H.; Yanagida, S.; Kamat, P. V. J. Phys. Chem. B 1999, $103,2589$.

(19) Takahashi, H.; Niidome, Y.; Sato, T.; Yamada, S. Colloids Surf., A 2004, 247, 105 .

(20) Redmond, P. L.; Hallock, A. J.; Brus, L. E. Nano Lett. 2005, 5 , 131.

(21) Zhang, X.; Hicks, E. M.; Zhao, J.; Schatz, G. C.; Van Duyne, R. P. Nano Lett. 2005, 5, 1503.

(22) Popov, K. I.; Pavlovic, M. G.; Grgur, B. N. J. Appl. Electrochem. 1998, 28, 797.

(23) Bek, R. Y.; Shuraeva, L. I. Russ. J. Electrochem. 2004, 40, 704.

(24) Cotton, F. A.; Wilkinson, G.; Murillo, C. A.; Bochmann, M. Advanced Inorganic Chemistry; John Wiley \& Sons: New York, 1999.

(25) Kolb, D. M.; Przasnyski, M.; Gerischer, H. Electroanal. Chem. Interfacial Electrochem. 1974, 54, 25.

(26) Zhang, J.; Sung, Y.-E.; Rikvold, P. A., Wieckowski, A. J. Chem. Phys. 1996, 104, 5699.

(27) Bard, A. J.; Faulkner, L. R. Electrochemical Methods, 2nd ed.; John Wiley \& Sons: New York 2001; 103.

(28) Grishko, V. I.; Duley, W. W.; Gu, Z. H.; Fahidy, T. Z. Electrochim. Acta 2001, 47, 643.

(29) Wee, L. M.; Li, L. Appl. Surf. Sci. 2005, 247, 285.

(30) Von Gutfeld, R. J.; Sheppard, K. G. IBM J. Res. Dev. 1998, 42, 639.

(31) Delahay, P. Double Layer Electrode Kinetics; John Wiley \& Sons: New York, 1965; p 154.

(32) Eyring, H.; Glasstone, S.; Laidler, K. J. J. Chem. Phys. 1939, 7, 1053

(33) Varvara, S.; Muresan, L.; Nicoara, A.; Maurin, G.; Popescu, I. C. Mater. Chem. Phys. 2001, 72, 332

(34) Lewandowski, A.; Gritzner, G. J. Chem. Soc., Faraday Trans. 1993, $89,3553$.

(35) Carslaw, H. S.; Jaeger, J. C. Conduction of Heat in Solids; Oxford University Press: New York, 1959.

(36) Link, S.; Burda, C.; Nikoobakht, B.; El-Sayed, M. A. J. Phys. Chem. B 2000, 104, 6152 .

(37) Takami, A.; Kurita, H.; Koda, S. J. Phys. Chem. B 1999, 103, 1226.

(38) Hodak, J. H.; Henglein, A.; Giersig, M.; Hartland, G. V. J. Phys. Chem. B 2000, 104, 11708 .

(39) Jiang, J.; Bosnick, K.; Maillard, M.; Brus, L. J. Chem. Phys. B 2003, 107, 9964.

(40) Otto, A. J. Raman Spectrosc. 2005, 36, 497.

(41) For a general review, see Zhu, X.-Y. J. Phys. Chem. B 2004, 108, 8778 .

(42) Rishelson, N.; Shkrob, I.; Lev, O.; Gun, J.; Modestov, A. D. Langmuir 2001, 17, 403 .

(43) McFarland, E.; Tang, J. Nature 2003, 421, 616

(44) Tian, Y.; Tatsuma, T. Chem. Commun. 2004, 1810.

(45) Tian, Y.; Tatsuma, T. J. Am. Chem. Soc. 2005, 127, 7632.

(46) Bauer, C.; Abid, J.-P.; Fermin, D.; Girault, H. H. J. Chem. Phys. 2004, 120, 9302 .

(47) Bauer, C.; Abid, J.-P.; Girault, H. H. J. Phys. Chem. B. 2006, 110, 4519.

(48) Murakoshi, K.; Tanaka, H.; Sawai, Y.; Nakato, Y. Surf. Sci. 2003, $532-535,1109$.

(49) Inasawa, S.; Sugiyama, M.; Yamaguchi, Y. J. Phys. Chem. B 2004, 109, 3104.

(50) Bjerneld, E. J.; Murty, K. V. G. K.; Prikulis, J.; Kall, M. Chem. Phys. Chem. 2002, 1, 116. 